\title{
Central bank policy rates: Are they cointegrated? ${ }^{\text {ir }}$
}

\author{
Guglielmo Maria Caporale ${ }^{\mathrm{a}, *},{\text { Hector } \text { Carcel }^{\mathrm{b}} \text {, Luis Gil-Alana }}^{\mathrm{b}}$ \\ a Brunel University London, UK \\ ${ }^{\mathrm{b}}$ University of Navarra, Spain
}

\section{A R T I C L E I N F O}

\section{JEL classification:}

$\mathrm{C} 22$

C32

E47

Keywords:

Interest rates

Long memory

Fractional integration and cointegration

\begin{abstract}
A B S T R A C T
This paper analyses the stochastic properties of the bilateral linkages between the central bank policy rates of the US, the Eurozone, Australia, Canada, Japan and the UK using fractional integration and cointegration techniques respectively. The univariate analysis suggests a high degree of persistence in all cases: the fractional integration parameter $\mathrm{d}$ is estimated to be above 1 , ranging from 1.26 (US) to 1.48 (UK), with the single exception of Japan, for which the unit root null cannot be rejected. Concerning the bivariate results, Australian interest rates are found to be cointegrated with the Eurozone and UK ones, Canadian rates with the UK and US ones, and Japanese rates with the UK ones. The increasing degree of integration of international financial markets and the coordinated monetary policy responses following the global financial crisis might both account for such linkages.
\end{abstract}

\section{Introduction}

Interest rate linkages have been analysed in numerous empirical studies. There are two main ways to interpret them (see Barassi et al., 2005). If interest rates are viewed as similar to other asset prices, then financial flows should be their main determinant. In particular, the uncovered interest parity condition (or the open arbitrage condition) implies that interest rate differentials should equal the (expected) change in exchange rates. Therefore if exchange rates are at most I(1) series (a common finding in the literature for the G-7), and if the risk premium is stationary, one should find that interest rates are cointegrated on a bilateral basis. It is noteworthy that in recent years many countries have liberalized their capital accounts, and there has been a shift in capital flows towards portfolio and other short-term flows. Cross-border capital flows have risen in search of higher yields given the low interest rates resulting from a global liquidity surplus. It has been suggested that these recent developments in international financial markets and their increasing globalization might have led to interest rate convergence.

By contrast, if interest rates are seen as policy instruments, policy objectives should be their main driving factor, and therefore co-movement should result from policy convergence. A key question is the extent to which domestic monetary authorities can still conduct an independent interest rate policy despite the fact that international financial markets have become increasingly integrated. Another important issue is whether the creation of EMU and the role of the euro as an international currency has resulted in the Eurozone having a more global role.

The present study focuses on central bank policy rates in the US, Japan, the Eurozone, the UK, Canada and Australia, and makes a twofold contribution. First, it applies long-memory techniques to provide evidence on the stochastic properties (in particular, the degree of persistence) of the interest rates series. Second, it examines their long-run linkages on a bilateral basis using a cointegration approach. Unlike the majority of earlier studies, it adopts a fractional integration/cointegration framework that is

\footnotetext{
Useful comments from the Editor and two anonymous reviewers are gratefully acknowledged.

* Correspondence to: Department of Economics and Finance, Brunel University London, UB8 3PH, UK.

E-mail address: Guglielmo-Maria.Caporale@brunel.ac.uk (G.M. Caporale).
} 
much more general than the standard approach based on the $\mathrm{I}(0) / \mathrm{I}(1)$ dichotomy since it allows for fractional values of the integration/cointegration parameter and therefore does not impose restrictive assumptions on the dynamic behaviour of the individual series and their linkages.

In recent years, several studies have stressed the importance of international spillovers in the conduct of monetary policy since the onset of the global financial crisis. For instance, Taylor (2013) argues that US monetary policy has deviated from the conventional Taylor rule and the potential costs of the deviation could be magnified through international spillovers. Using panel data techniques, other papers (e.g., Gray, 2013, Hofmann and Takats, 2013) found that US policy rates affect policy rates in other countries. These international monetary spillovers make costly US monetary policy for other countries. We address these issues in a time series context by using a general, flexible framework that allows for a possibly slow adjustment to the long-run equilibrium relationships.

The structure of the paper is as follows: Section 2 provides a brief review of the empirical literature on interest rates, focusing specifically on the stationarity/nonstationarity debate and its relation to fractional integration and cointegration; Section 3 outlines the empirical methodology; Section 4 describes the data and the main empirical findings; Section 5 offers some concluding remarks.

\section{Are interest rates stationary?}

The statistical properties of interest rates have been extensively analysed in the literature. Earlier studies usually focused on testing whether interest rates can be described as stationary I(0) or nonstationary I(1) series. For instance, Cox et al. (1985) concluded that the short-term nominal interest rate is a stationary and mean-reverting I(0) process, whereas Campbell and Shiller (1987) found that they exhibit a unit root. A drawback of $\mathrm{I}(0)$ models is that they imply long-term rates that are not volatile enough (Shiller, 1979), whereas a problem with I(1) models is that they imply that the term premium increases with bond maturities (Campbell, Law and MacKinlay, 1997). Other studies have analysed whether or not real rates are stationary, since a unit root in exante real rates is inconsistent not only with the Fisher hypothesis but also with the consumption-based capital asset pricing model (CCAPM) of Lucas (1978) (see Rose, 1988). Various papers in the earlier literature found a unit root in the real interest rate (see, e.g., Goodwin and Grennes, 1994; Phylaktis, 1999; Rapach and Wohar, 2004).

However, the low power and limitations of traditional unit root testing methods are now well known. More recent studies have tried to deal with these issues by using long-horizon data (see, e.g., Sekioua and Zakane, 2007), or applying long-memory or fractional integration approaches. These are much more flexible than the usual $\mathrm{I}(0) / \mathrm{I}(1)$ framework, since they allow the degree of integration to be between 0 and 1 , as well as above 1 . This is particularly useful for series which, although mean-reverting, might exhibit long memory and therefore be characterized by a high degree of persistence. For example, Shea (1991) investigated the consequences of long memory in interest rates for tests of the expectations hypothesis of the term structure; he found that allowing for long memory and fractional integration can significantly improve the performance of the model, even though the expectations hypothesis cannot be fully resurrected. In a related study, Backus and Zin (1993) reported that the volatility of bond yields does not decline exponentially when the maturity of the bond increases; in fact, they noticed that the decline is hyperbolic, which is consistent with a fractionally integrated specification. Lai (1997) provided evidence based on semi-parametric methods that ex-ante and expost US real interest rates are fractionally integrated. Tsay (2000) employed an Autoregressive Fractionally Integrated Moving Average (ARFIMA) model to show that US real interest rates can be described as an I(d) process. Further evidence can be found in Barkoulas and Baum (1997), Tkacz (2001), Meade and Maier (2003), Sun and Phillips (2004), Gil-Alana (2004a, 2004b), and Karanasos et al. (2006). Couchman et al. (2006) estimated ARFIMA models for ex-post and ex-ante interest rates in sixteen countries. Their results suggest that, for the majority of countries, the fractional differencing parameter lies between 0 and 1 , and is considerably smaller for the ex-post than for the ex-ante real rates.

Fractional cointegration tests have also been employed in recent studies. Lardic and Mignon (2003) tested for fractional cointegration between nominal interest rates and inflation under the assumption that both individual series were I(1). They tested this hypothesis with standard unit root procedures (Dickey and Fuller, 1979; Phillips and Perron, 1988; and the Kwiatkowski et al., 1992 tests). However, these methods have extremely low power if the alternatives are of a fractional form (Diebold and Rudebusch, 1991; Hassler and Wolters, 1994; Lee and Schmidt, 1996). Barkoulas and Baum (1997) also used fractional integration to model nominal interest rates and found evidence of long memory in the differenced series. Mean reversion in nominal rates was reported for Asian and emerging countries respectively in Gil-Alana (2004a) and Candelon and Gil-Alana (2006).

\section{Fractional integration and cointegration}

As already mentioned, a fractional integration approach, rather than imposing integer degrees of differentiation, allows for real values including fractional ones. If $\left\{\mathrm{x}_{\mathrm{t}}, \mathrm{t}=1,2, \ldots\right]$ is the series of interest, the model is specified as:

$$
(1-L)^{d} x_{t}=u_{t}, t=1,2, \ldots
$$

where $\mathrm{L}$ is the lag operator (i.e., $\left.\mathrm{Lx}_{\mathrm{t}}=\mathrm{x}_{\mathrm{t}-1}\right)$, $\mathrm{d}$ can be any real number, and $\mathrm{u}_{\mathrm{t}}$ assumed to be integrated of order 0 , denoted by $\mathrm{I}(0)$, and defined as a covariance stationary process with a finite value for the infinite sum of the autocovariances. In this context, $\mathrm{x}_{\mathrm{t}}$ is said to be I(d), and the differencing parameter d plays a crucial role in determining the degree of dependence of the series. The higher the value of $d$ is the higher the dependence between observations distant in time will be. Moreover, values of $d$ below 1 indicate that shocks have transitory effects, whereas values of d equal to or higher than 1 imply permanent effects.

The methodology employed here to estimate the differencing parameter is based on the Whittle function in the frequency 


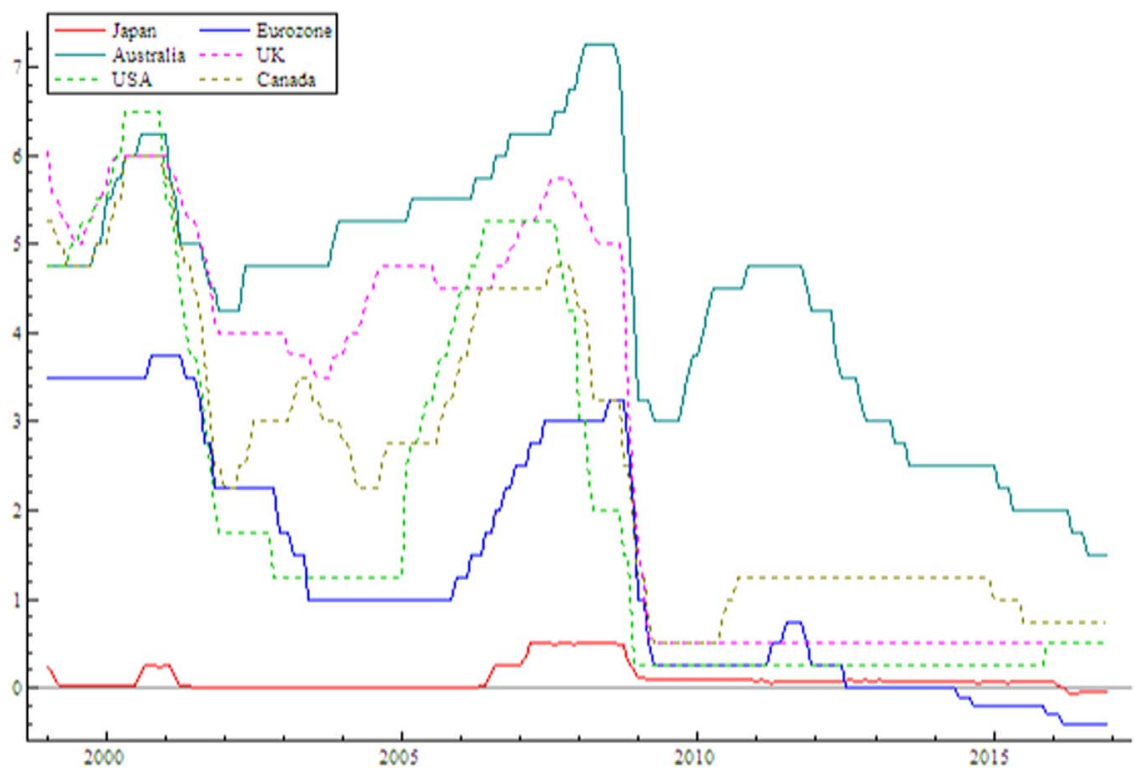

Fig. 1. Interest Rates in Levels.

domain; we use both parametric (Dahlhaus, 1989; Robinson, 1994) and semi-parametric (Robinson, 1995a, 1995b; Abadir et al., 2007) methods. Additionally, other standard approaches in the time domain (Sowell, 1992; Beran, 1995) are also followed.

In order to examine bivariate relationships homogeneity in the order of integration of the series should be tested in the first instance. For this purpose, we follow the Robinson and Yajima's (2002) approach, which has a standard normal limit distribution (see Gil-Alana and Hualde (2009) for evidence on the finite sample performance of this procedure). If homogeneity is found, then the Hausman test for no cointegration of Marinucci and Robinson (2001) is performed; this compares the Whittle estimates of d for the individual series with the more efficient bivariate one of Robinson (1995b), which uses the information that $d_{x}=d_{y}=d_{*}$. Marinucci and Robinson (2001) show heuristically that this statistic has a standard limit distribution. The Fractional Cointegration VAR approach (FCVAR) of Johansen and Nielsen (2012) is also applied below, the present study being the first one analysing policy interest rates using this methodology.

\section{Data and empirical results}

The series analyzed are the central bank policy rates, monthly, from January 1999 to December 2016, for the US (the Federal funds target rate), Japan (the target call rate), the Eurozone (the Repo rate), the UK (the base rate), Canada (the target rate) and Australia (the target cash rate); the data sources are the corresponding Central Banks. We focus on monthly rather than higher frequency data because most variations of central bank interests do not take place very frequently.

Fig. 1 displays the time series plots of the interest rate series, and clearly shows the quantitative easing measures that Western central banks have been forced to adopt in recent years.

The first step in our analysis is the estimation of the (fractional) differencing parameter. We start with a parametric testing approach that is based on the Whittle function in the frequency domain (Robinson, 1994). Using this method, we test the null hypothesis

$$
H_{o}: d=d_{o}
$$

Table 1

Estimated values of $d$ and 95\% confidence bands with white noise errors.

\begin{tabular}{llll}
\hline & No regressors & An intercept & A linear trend \\
\hline AUSTRALIA & $1.11(1.02,1.21)$ & $\mathbf{1 . 4 3 ( 1 . 3 3 , \mathbf { 1 . 5 5 } )}$ & $1.43(1.33,1.55)$ \\
CANADA & $1.07(0.98,1.17)$ & $\mathbf{1 . 3 5}(\mathbf{1 . 2 6 , \mathbf { 1 . 4 4 } )}$ & $1.35(1.26,1.44)$ \\
EUROZONE & $1.09(1.00,1.19)$ & $\mathbf{1 . 2 8}(\mathbf{1 . 2 0 , 1 . 3 9 )}$ & $1.28(1.20,1.39)$ \\
JAPAN & $1.23(1.11,1.40)$ & $\mathbf{1 . 4 0}(\mathbf{1 . 2 7}, \mathbf{1 . 5 8})$ & $1.40(1.27,1.58)$ \\
UNITED KINGDOM & $1.04(0.96,1.14)$ & $\mathbf{1 . 6 6 ( 1 . 5 3 , \mathbf { 1 . 8 2 } )}$ & $1.67(1.54,1.84)$ \\
UNITED STATES & $1.10(1.03,1.19)$ & $\mathbf{1 . 2 4}(\mathbf{1 . 1 7}, \mathbf{1 . 3 1})$ & $1.24(1.17,1.31)$ \\
\hline
\end{tabular}

The values in bold refer to the significant models according to the deterministic terms. The values in parentheses refer to the $95 \%$ confidence intervals for the differencing parameters. 
Table 2

Estimated values of $\mathrm{d}$ and $95 \%$ confidence bands with autocorrelated errors.

\begin{tabular}{lll}
\hline & No regressors & An intercept \\
\hline AUSTRALIA & $1.09(0.93,1.30)$ & $\mathbf{1 . 3 6}(\mathbf{1 . 1 3}, \mathbf{1 . 6 5})$ \\
CANADA & $1.06(0.92,1.26)$ & $\mathbf{1 . 5 3}(\mathbf{1 . 3 2}, \mathbf{1 . 8 1})$ \\
EUROZONE & $1.10(0.96,1.32)$ & $\mathbf{1 . 4 0}(\mathbf{1 . 1 9}, \mathbf{1 . 7 2 )}$ \\
JAPAN & $0.88(0.74,1.05)$ & $\mathbf{1 . 0 1}(\mathbf{0 . 8 3 , 1 . 2 1 )}$ \\
UNITED KINGDOM & $1.05(0.93,1.25)$ & $\mathbf{1 . 3 0}(\mathbf{1 . 1 3}, \mathbf{1 . 5 5 )}$ \\
UNITED STATES & $1.23(1.06,1.38)$ & $\mathbf{1 . 5 4}(\mathbf{1 . 3 6}, \mathbf{1 . 7 4 )}$ \\
\hline
\end{tabular}

The values in bold refer to the significant models according to the deterministic terms. The values in parentheses refer to the $95 \%$ confidence intervals for the differencing parameters.

for given real values $\mathrm{d}_{\mathrm{o}}$, in the model given by Eq. (3) below, under the assumption of white noise and autocorrelated disturbances respectively. In the latter case we implement the non-parametric method of Bloomfield (1973) that produces autocorrelation values decaying exponentially as in the autoregressive case. The model specification is the following:

$$
y_{t}=\alpha+\beta t+x_{t} ; \quad(1-L)^{d} x_{t}=u_{t}, \quad t=1,2, \ldots,
$$

where $y_{t}$ is the observed time series for each country, $\alpha$ and $\beta$ are the unknown coefficients on an intercept and a linear trend, and the errors, $x_{t}$, are assumed to be I(d). There are several arguments in favor of using Robinson's (1994) approach. First, it is a Lagrange Multiplier (LM) procedure, with the computational advantage that it does not require a consistent estimate of the differencing parameter. Moreover, it allows to test any real value $d_{o}$, including stationary $\left(d_{o}<0.5\right)$ and non-stationary $\left(d_{o} \geq 0.5\right)$ cases, and the limiting distribution is standard normal. In addition the distribution is normal regardless of the inclusion or not of deterministic terms and of the different specifications for the error term.

Table 1 reports the results for white noise errors while Table 2 focuses on the case of Bloomfield-type disturbances; for both we consider the three standard cases of i) no deterministic terms, $(\alpha=\beta=0$ in(2)), an intercept ( $\alpha$ unknown and $\beta=0)$ and an intercept with a linear time trend ( $\alpha$ and $\beta$ unknown). We report in the table the values of $\mathrm{d}_{\mathrm{o}}$ producing the lowest statistic in absolute value using Robinson's (1994) approach. This value is almost identical to the Whittle estimate obtained by taking first differences and then adding the value 1 to the estimated value. In addition, we also report the 95\% confidence band corresponding to the non-rejection values of $d_{o}$ testing (2) in (3). An intercept seems to be sufficient to describe the deterministic components of the series. In the white noise case, the unit root hypothesis (i.e., $\mathrm{d}=1$ ) is rejected in all cases, with the value of $\mathrm{d}$ being significantly above 1 , ranging from 1.24 (US) to 1.66 (UK).

Very similar results are obtained with (weakly) autocorrelated errors: the unit root null hypothesis is rejected in all cases in favor of $d>1$ except for Japan ( $\mathrm{d}=1.01$ ); in the other cases, $d$ ranges between 1.30 (UK) and 1.54 (US).

We also employ a semi-parametric approach based on a "local" Whittle estimate that degenerates to zero (Robinson, 1995a). We report in Table 3 the values of $\mathrm{d}$ for a selected number of bandwidth parameters from $\mathrm{m}=10-20$. Focusing on those where $\mathrm{m}$ is approximately $(\mathrm{T})^{0.5}$, i.e., 14 and 15,one can see that the unit root null cannot be rejected for Australia, the Eurozone, Japan and the UK, whilst it is in the remaining cases in favor of higher degrees of integration. Similar results were obtained using the extension of this method as in Abadir et al. (2007). On the whole, the univariate results indicate a high degree of persistence, with orders of integration equal to or higher than 1 in all cases, which implies that shocks have permanent effects.

Next we carry out the bivariate analysis. Tables 4 and 5 report the statistics of Robinson and Yajima (2002) for the equality in the order of integration using respectively $\mathrm{m}=14$ and $\mathrm{m}=15$ as the bandwidth parameters. With $\mathrm{m}=14$, Australia displays the same degree of integration as the Eurozone; the order of integration for the Eurozone is statistically similar to the one of Japan and the UK, and the same happens with Japan with respect to the UK. If $\mathrm{m}=15$, along with the above cases, Canada displays the same orders of integration as Japan and the UK. Exactly the same combination of countries were obtained when using other methods like the one suggested by Hualde (2013).

The cointegration results (again for $\mathrm{m}=14$ and $\mathrm{m}=15$ respectively) are reported in Tables 6 and 7 . Australia is found to be

Table 3

Estimates of d based on a "local" Whittle semiparametric method.

\begin{tabular}{|c|c|c|c|c|c|c|c|c|c|c|c|}
\hline $\mathrm{m}$ & 10 & 11 & 12 & 13 & 14 & 15 & 16 & 17 & 18 & 19 & 20 \\
\hline AUSTRALIA & 0.645 & 0.686 & 0.703 & 0.771 & 0.840 & 0.972 & 0.983 & 1.063 & 1.148 & 1.193 & 1.239 \\
\hline CANADA & 0.849 & 1.017 & 1.176 & 1.228 & 1.340 & 1.209 & 1.319 & 1.280 & 1.294 & 1.317 & 1.273 \\
\hline EUROZONE & 1.003 & 1.115 & 0.975 & 1.017 & 1.041 & 1.052 & 1.101 & 1.113 & 1.126 & 1.121 & 1.113 \\
\hline JAPAN & 1.084 & 1.085 & 1.039 & 1.118 & 1.102 & 1.149 & 1.096 & 1.069 & 1.032 & 0.992 & 1.019 \\
\hline U. K. & 0.996 & 1.073 & 1.151 & 1.118 & 1.179 & 1.148 & 1.191 & 1.172 & 1.184 & 1.196 & 1.192 \\
\hline U.S.A. & 1.479 & 1.500 & 1.500 & 1.500 & 1.500 & 1.486 & 1.489 & 1.500 & 1.477 & 1.440 & 1.451 \\
\hline $95 \%$ low & 0.739 & 0.752 & 0.762 & 0.771 & 0.780 & 0.787 & 0.794 & 0.800 & 0.806 & 0.811 & 0.816 \\
\hline 95\% high & 1.260 & 1.247 & 1.237 & 1.228 & 1,219 & 1.212 & 1.205 & 1.199 & 1.193 & 1.188 & 1.183 \\
\hline
\end{tabular}

The values in the first row are the bandwidth numbers. Note that $\mathrm{m}=(\mathrm{T})^{0.5}=12.40$. 
Table 4

Homogeneity condition tests (Robinson and Yajima, 2002).

\begin{tabular}{|c|c|c|c|c|c|}
\hline $\mathrm{m}=14$ & CANADA & EUROZONE & JAPAN & U.K. & U.S.A. \\
\hline AUSTRALIA & -5.60 & -1.41 & -2.26 & -3.34 & -7.84 \\
\hline CANADA & $\mathrm{xxx}$ & 4.18 & 3.32 & 2.25 & -2.24 \\
\hline EUROZONE & $\mathrm{xxx}$ & $\mathrm{xxx}$ & -0.85 & -1.93 & -6.42 \\
\hline JAPAN & $\mathrm{xxx}$ & $\mathrm{xxx}$ & $\mathrm{xxx}$ & -1.07 & -5.57 \\
\hline U.K. & $\mathrm{xxx}$ & $\mathrm{xxx}$ & $\mathrm{xxx}$ & $\mathrm{xxx}$ & -4.49 \\
\hline
\end{tabular}

$\mathrm{m}$ is the bandwidth parameter and the values in bold indicate no rejection of the homogeneity condition at the $5 \%$ level.

cointegrated with the Eurozone, Japan and the UK with $\mathrm{m}=14$ but only with the UK with $\mathrm{m}=15$; Canada with the Eurozone UK and the US for the two bandwidth numbers, and Japan with the Eurozone. In all these cases, the reduction in the degree of integration is quite small (around $0.2-0.3$ with respect to the parent series), indicating slow mean reversion in the dynamic adjustment towards the long-run equilibrium.

Next we report the results obtained using the recently introduced FCVAR model of Nielsen and Johansen (2012). Table 8 reports cointegration rank tests: the null of a cointegrating rank of 2 could not be rejected. After selecting 3 as the appropriate lag length on the basis of standard information criteria and 2 as the cointegrating rank, the following two FVECM models were obtained:

$$
\begin{gathered}
\Delta^{0.945}\left(\left(\begin{array}{l}
\text { Japan } \\
\text { Eurozone } \\
\text { Australia } \\
\text { UK } \\
\text { USA } \\
\text { Canada }
\end{array}\right)-\left(\begin{array}{l}
0.234 \\
3.431 \\
4.675 \\
55.946 \\
4.733 \\
5.288
\end{array}\right)\right)=L_{0.945}\left(\begin{array}{l}
0.008 \\
0.063 \\
0.063 \\
-91.61 \\
0.010 \\
-0.089
\end{array}\right) v_{t}+\sum_{i=1}^{3} \Gamma_{i} \Delta^{0.945} L_{0.945}^{i}\left(X_{t}-\mu\right)+\varepsilon_{t} \\
\left.\Delta^{0.945}\left(\begin{array}{l}
\text { Japan } \\
\text { Eurozone } \\
\text { Australia } \\
\text { UK } \\
\text { USA } \\
\text { Canada }
\end{array}\right)-\left(\begin{array}{l}
0.234 \\
3.431 \\
4.675 \\
55.946 \\
4.733 \\
5.288
\end{array}\right)\right)=L_{0.945}\left(\begin{array}{l}
-0.009 \\
-0.069 \\
-0.061 \\
-74.49 \\
-0.030 \\
0.097
\end{array}\right) v_{t}+\sum_{i=1}^{3} \Gamma_{i} \Delta^{0.945} L_{0.945}^{i}\left(X_{t}-\mu\right)+\varepsilon_{t}
\end{gathered}
$$

The estimated value of $d$ higher than 0.5 is consistent with the results in Tables 6 and 7 , and implies reversion to the long-run equilibrium relationship between interest rates. The VECM models can also be used for forecasting purposes. However, since they are not structural models, they cannot shed light on the economic mechanisms behind mean reversion. What is clear from the findings above, though, is that despite cross-country differences in monetary policy and financial regulation there are long-run linkages between interest rates. The evidence of long memory suggests that their paths might diverge even over long time spans as a result of such differences; however, eventually they will converge since mean reversion will occur; this reflects the process of globalization and increasing financial integration of the world economy and of the international financial markets.

\section{Conclusions}

This paper analyses the stochastic properties of and the bilateral linkages between the central bank policy rates of the US, the Eurozone, Australia, Canada, Japan and the UK using fractional integration and cointegration techniques respectively; this approach allows for much richer dynamics than the classical models based on the $\mathrm{I}(0) / \mathrm{I}(1)$ dichotomy. The univariate analysis suggests a high degree of persistence in all cases: the fractional integration parameter $\mathrm{d}$ is estimated to be above 1 , ranging from 1.26 (US) to 1.48 (UK), with the single exception of Japan, for which the unit root null cannot be rejected; therefore it appears that interest rates are not mean-reverting, with shocks having permanent effects, a finding clearly important for the design of appropriate monetary policies.

Concerning the bivariate results, Australian interest rates are found to be cointegrated with the Eurozone and UK ones, Canadian

Table 5

\begin{tabular}{|c|c|c|c|c|c|}
\hline $\mathrm{m}=15$ & CANADA & EUROZONE & JAPAN & U.K. & U.S.A. \\
\hline AUSTRALIA & -3.55 & -1.20 & -2.65 & -2.63 & -7.71 \\
\hline CANADA & $\mathrm{xxx}$ & 2.35 & 0.89 & 0.91 & -4.15 \\
\hline EUROZONE & $\mathrm{xxx}$ & $\mathrm{xxx}$ & -1.45 & -1.44 & -6.50 \\
\hline JAPAN & $\mathrm{xxx}$ & $\mathrm{xxx}$ & $\mathrm{xxx}$ & 0.01 & -5.05 \\
\hline U.K. & $\mathrm{xxx}$ & $\mathrm{xxx}$ & $\mathrm{xxx}$ & $\mathrm{xxx}$ & -5.07 \\
\hline
\end{tabular}

Homogeneity condition tests (Robinson and Yajima, 2002).

$\mathrm{m}$ is the bandwidth parameter and the values in bold indicate no rejection of the homogeneity condition at the $5 \%$ level. 
Table 6

Testing the null hypothesis of no cointegration against fractional cointegration.

\begin{tabular}{|c|c|c|c|c|}
\hline $\mathrm{m}=14$ & EUROZONE & JAPAN & U.K. & U.S.A. \\
\hline \multirow[t]{5}{*}{ AUSTRALIA } & $\mathrm{H}_{10}: \mathbf{1 . 6 6 7}$ & $H_{10}: 1.892$ & $\mathrm{H}_{10}: \mathbf{3 . 8 7 4}$ & xxxxx \\
\hline & $H_{20}: 5.569$ & $\mathrm{H}_{20}: 9.545$ & $\mathrm{H}_{20}: 20.231$ & \\
\hline & $\mathrm{d}_{1}=0.940$ & $d_{1}=0.940$ & $\mathrm{~d}_{1}=0.940$ & \\
\hline & $d_{2}=1.041$ & $d_{2}=1.102$ & $\mathrm{~d}_{2}=1.179$ & \\
\hline & $\mathrm{d}_{*}=\mathbf{0 . 8 1 8}$ & $\mathrm{d}_{*}=\mathbf{0 . 8 1 0}$ & $\mathrm{d}_{*}=\mathbf{0 . 8 5 4}$ & \\
\hline \multirow[t]{5}{*}{ CANADA } & $H_{10}: 51.030$ & $\mathrm{H}_{10}: 6.59$ & $H_{10}: 41.402$ & $H_{10}: 43.750$ \\
\hline & $H_{20}: 15.834$ & $\mathrm{H}_{20}: 0.001$ & $\mathrm{H}_{20}: 22.370$ & $\mathrm{H}_{20}: 69.017$ \\
\hline & $\mathrm{d}_{1}=1.340$ & $\mathrm{~d}_{1}=1.340$ & $\mathrm{~d}_{1}=\mathbf{1 . 3 4 0}$ & $\mathrm{d}_{1}=\mathbf{1 . 3 4 0}$ \\
\hline & $d_{2}=1.041$ & $\mathrm{~d}_{2}=1.102$ & $d_{2}=1.179$ & $\mathrm{~d}_{2}=1.500$ \\
\hline & $\mathrm{d}_{*}=0.665$ & $\mathrm{~d}_{*}=1.098$ & $\mathrm{~d}_{*}=0.732$ & $d_{*}=0.715$ \\
\hline \multirow[t]{5}{*}{ EUROZONE } & $\operatorname{xxxxx}$ & $H_{10}: 3.833$ & $\mathrm{H}_{10}: 0.001$ & $\mathrm{xxxxx}$ \\
\hline & & $\mathrm{H}_{20}: 6.777$ & $\mathrm{H}_{20}: 2.011$ & \\
\hline & & $d_{1}=1.041$ & $\mathrm{~d}_{1}=1.041$ & \\
\hline & & $d_{2}=1.102$ & $\mathrm{~d}_{2}=1.179$ & \\
\hline & & $\mathrm{d}_{*}=\mathbf{0 . 8 5 6}$ & $\mathrm{d}_{*}=1.045$ & \\
\hline \multirow[t]{5}{*}{ JAPAN } & $\operatorname{xxxxx}$ & $\mathrm{xxxxx}$ & $\mathrm{H}_{10}: 1.142$ & $\mathrm{xxxxx}$ \\
\hline & & & $\mathrm{H}_{20}: 1.120$ & \\
\hline & & & $\mathrm{d}_{1}=1.102$ & \\
\hline & & & $\mathrm{d}_{2}=1.179$ & \\
\hline & & & $\mathrm{d}^{*}=1.081$ & \\
\hline
\end{tabular}

In bold the cases with significant evidence of (fractional) cointegration at the $5 \%$ level.

rates with the UK and US ones, and Japanese rates with the UK ones. The results obtained with the multivariate FCVAR approach of Nielsen and Johansen (2012) are completely in line with the bivariate ones, and provide evidence of reversion to the long-run equilibrium relationships. As pointed out previously, such linkages can be interpreted alternatively as the result of capital flows or policy convergence. Both factors are likely to have played a role over the sample period examined, during which international financial markets became increasingly integrated, and the global financial crisis led to similar, coordinated monetary policy responses (low interest rates, quantitative easing) aimed at injecting liquidity into the system and preventing the collapse of the banking system and stimulating the economy. The ability of national monetary authorities to conduct independent policies (for instance, for stabilization purposes) has possibly been curtailed in the circumstances. Not surprisingly, linkages are found between US and Canada, two tightly connected economies. There is limited evidence of the supposedly more global effects of developments in the Eurozone, since linkages are found only with Australian rates; it is the UK instead that appears to have a more global role, perhaps because of the size of its financial sector.

It is noteworthy that cointegration between interest rates implies that both liquidity issues and the pricing of risk should be considered and addressed as required at the global rather than the national level, since cointegration implies that in the long run

Table 7

Testing the null hypothesis of no cointegration against fractional cointegration.

\begin{tabular}{|c|c|c|c|c|}
\hline $\mathrm{m}=15$ & EUROZONE & JAPAN & U.K. & U.S.A. \\
\hline \multirow[t]{5}{*}{ AUSTRALIA } & $\mathrm{H}_{10}: 0.571$ & $\mathrm{H}_{10}: 0.554$ & $\mathrm{H}_{10}: 4.423$ & $\mathrm{Xxxxx}$ \\
\hline & $\mathrm{H}_{20}: 2.664$ & $\mathrm{H}_{20}: 7.203$ & $H_{20}: 16.250$ & \\
\hline & $\mathrm{d}_{1}=0.972$ & $\mathrm{~d}_{1}=0.972$ & $\mathrm{~d}_{1}=0.972$ & \\
\hline & $\mathrm{d}_{2}=1.052$ & $\mathrm{~d}_{2}=1.149$ & $d_{2}=1.148$ & \\
\hline & $\mathrm{d}_{*}=0.903$ & $\mathrm{~d}_{*}=0.974$ & $\mathrm{~d}_{*}=\mathbf{0 . 8 8 0}$ & \\
\hline \multirow[t]{5}{*}{ CANADA } & $H_{10}: 25.171$ & $\mathrm{H}_{10}: 3.591$ & $H_{10}: 20.270$ & $H_{10}: 20.073$ \\
\hline & $\mathrm{H}_{20}: 10.872$ & $\mathrm{H}_{20}: 1.532$ & $H_{20}: 14.700$ & $\mathrm{H}_{20}: 56.471$ \\
\hline & $\mathrm{d}_{1}=1.209$ & $\mathrm{~d}_{1}=1.209$ & $\mathrm{~d}_{1}=1.209$ & $\mathrm{~d}_{1}=1.209$ \\
\hline & $d_{2}=1.052$ & $\mathrm{~d}_{2}=1.149$ & $d_{2}=1.148$ & $\mathrm{~d}_{2}=1.486$ \\
\hline & $d_{*}=0.751$ & $\mathrm{~d}_{*}=1.036$ & $d_{*}=0.798$ & $\mathrm{~d}_{*}=\mathbf{0 . 8 0 0}$ \\
\hline \multirow[t]{5}{*}{ EUROZONE } & $\operatorname{xxxxx}$ & $\mathrm{H}_{10}: 5.241$ & $\mathrm{H}_{10}: 0.001$ & $\operatorname{xxxxx}$ \\
\hline & & $\mathrm{H}_{20}: 11.236$ & $\mathrm{H}_{20}: 1.129$ & \\
\hline & & $d_{1}=1.052$ & $\mathrm{~d}_{1}=1.052$ & \\
\hline & & $\mathrm{d}_{2}=1.149$ & $\mathrm{~d}_{2}=1.148$ & \\
\hline & & $\mathrm{d}_{*}=0.843$ & $\mathrm{~d}_{*}=1.051$ & \\
\hline \multirow[t]{5}{*}{ JAPAN } & $\mathrm{xxxxx}$ & $\mathrm{xxxxx}$ & $\mathrm{H}_{10}: 1.224$ & $\mathrm{xxxxx}$ \\
\hline & & & $\mathrm{H}_{20}: 1.200$ & \\
\hline & & & $\mathrm{d}_{1}=1.149$ & \\
\hline & & & $\mathrm{d}_{2}=1.148$ & \\
\hline & & & $\mathrm{d}_{*}=1.048$ & \\
\hline
\end{tabular}

In bold the cases with significant evidence of (fractional) cointegration at the $5 \%$ level. 
Table 8

Results based on FCVAR approach.

\begin{tabular}{lll}
\hline Rank & Log-Likelihood & LR statistic \\
\hline 0 & -753.081 & 107.519 \\
1 & $-723.78248 .921-$ & 48.921 \\
$\mathbf{2}$ & $20.9450 .945-708.630$ & $\mathbf{1 8 . 6 1 7}$ \\
3 & $-\mathbf{7 0 4 . 2 0 8}$ & 9.772 \\
4 & -704.208 & 4.220 \\
5 & -701.432 & 0.145 \\
& -699.394 & - \\
\hline
\end{tabular}

interest rates will have converged and therefore it is not possible for domestic authorities to pursue an independent monetary policy. A case in point is the recent global financial crisis. At first monetary easing (through lowering interest rates as well as adopting unconventional monetary policy measures such as QE, quantitative easing) was introduced by the Fed; subsequently the Bank of England, the ECB and other central banks had to follow suit adopting a similar approach and creating the current environment of extremely low interest rates and declining long-term yields, which reflect the slow pace of economic recovery, lower inflation rates and inflation expectations as well as accommodative monetary policy. The other important issue in this context is of course the existence of a "global liquidity trap", which means that optimal monetary policy is characterized by its international dependence; in particular, some recent research by Fujiwara et al. (2013) suggests that monetary authorities should target the price level rather than the inflation rate, and respond to prices and the output gap of other countries as well. It is clear, therefore, that it has become even more crucial to analyse monetary policy and interest rate linkages at the global level.

Finally, it is worth pointing out that in principle our results could be biased owing to the presence of time variation and/or undetected breaks. However, other approaches based on nonlinear trends still in the context of fractional integration (Cuestas and Gil-Alana, 2016) produced very similar findings.

\section{References}

Abadir, K.M., Distaso, W., Giraitis, L., 2007. Nonstationarity-extended local Whittle estimation. J. Econ. 141, 1353-1384.

Backus, D., Zin, S., 1993. Long memory inflation uncertainty. Evidence from the term structure of interest rates. J. Money Credit Bank. 25, 681-700.

Barassi, M.R., Caporale, G.M., Hall, S.G., 2005. Interest rate linkages: identifying structural relations. Appl. Financ. Econ. 15 (14), $977-986$.

Barkoulas, J.T., Baum, C.F., 1997. Fractional differencing modeling and forecasting of eurocurrency deposit rates. J. Financ. Res. 20 , 355-372.

Beran, J., 1995. Maximum likelihood estimation of the differencing parameter for invertible short and long memory ARIMA models. J. R. Stat. Soc. Ser. B 57, $659-672$.

Bloomfield, P., 1973. An exponential model in the spectrum of a scalar time series. Biometrika 60, 217-226.

Campbell, J.Y., Shiller, R.J., 1987. Cointegration and tests of present value models. J. Political Econ. 95, 1062-1088.

Campbell, J.Y., Law, A.W., MacKinlay, A.C., 1997. The Econometrics of the Financial Markets. Princeton University Press, Princeton, NJ.

Candelon, B., Gil-Alana, L.A., 2006. Mean reversion of short run interest rates in emerging countries. Rev. Int. Econ. 14, 119-135.

Couchman, J., Gounder, R., Su, J.J., 2006. Long memory properties of real interest rates for 16 countries. Appl. Financ. Econ. Lett. 2, 25-30.

Cox, J., Ingersoll, J., Ross, S., 1985. A theory of term structure of interest rates. Econometrica 53, 385-408.

Cuestas, J.C., Gil-Alana, L.A., 2016. A non-linear approach with long range dependence based on Chebyshev polynomials. Stud. Nonlinear Dyn. Econ. 23 , 445-468. Dahlhaus, R., 1989. Efficient parameter estimation for self-similar process. Ann. Stat. 17, 1749-1766.

Dickey, D.A., Fuller, W.A., 1979. Distribution of the estimators for autoregressive time series with a unit root. J. Am. Stat. Assoc. 74, 427-431.

Diebold, F.S., Rudebusch, G.D., 1991. On the power of Dickey-Fuller tests against fractional alternatives. Econ. Lett. 35, 155-160.

Fujiwara, I., Nakajima, T., Sudo, N., Teranishi, Y., 2013. Global liquidity trap. J. Monet. Econ. 60 (8), 936-949.

Gil-Alana, L.A., 2004a. Long memory in the interest rates in some Asian countries. Int. Adv. Econ. Res. 9, $257-267$.

Gil-Alana, L.A., 2004b. Long memory in the US interest rate. Int. Rev. Financ. Anal. 13, 265-276.

Gil-Alana, L.A., Hualde, J., 2009 Fractional integration and cointegration. An overview with an empirical application. In: The Palgrave Handbook of Applied Econometrics, vol. 2, pp. 434-472.

Goodwin, B.K., Grennes, T.J., 1994. Real interest rate equalization and the integration of international financial markets. J. Int. Money Financ. 13, $107-124$. Gray, C., 2013. Responding to a monetary superpower: investigating the behavioral spillovers of US monetary policy. Atl. Econ. Rev. 41 (2), 173-184, (Revised). Hassler, U., Wolters, J., 1994. On the power of unit root tests against fractional alternatives. Econ Lett 45, 1-5.

Hofmann, B., Takats, E., 2013. International monetary spillovers. Bank for International Settlements Quarterly Review, pp. 105-118. (September issue).

Hualde, J., 2013. A simple test for the equality in the integration orders. Econ. Lett. 119 (3), 233-237.

Johansen, S., Nielsen, M.O., 2012. Likelihood inference for a fractionally cointegrated vector autoregressive model. Econometrica 80 (6), $2667-2732$.

Karanasos, M., Sekioua, S., Zeng, N., 2006. On the order of integration of monthly US Ex-ante and Ex-post real interest rates: new evidence from over a century of data. Econ. Lett. 90, 163-169.

Kwiatkowski, D., Phillips, P.C.D., Schmidt, P., Shin, Y., 1992. Testing the null hypothesis of stationarity against the alternative of a unit root: how sure are we that economic time series have a unit root? J. Econ. 54, 159-178.

Lai, K.S., 1997. Long-term persistence in the real interest rate: some evidence of a fractional unit root. Int. J. Financ. Econ. 2 (3), $225-235$.

Lardic, S., Mignon, V., 2003. Fractional cointegration between nominal interest rates and Inflation: a Re-examination of the fisher relationship in the G7 countries. Econ. Bull. 3, 1-10.

Lee, D., Schmidt, P., 1996. On the power of the KPSS test of stationarity against fractionally integrated alternatives. J. Econ. 73, $285-302$.

Lucas, R.E., 1978. Asset prices in an exchange economy. Econometrica 46, 1429-1445.

Marinucci, D., Robinson, P.M., 2001. Semiparametric fractional cointegration analysis. J. Econ. 105, 225-247.

Meade, N., Maier, M.R., 2003. Evidence of long memory is short term interest rates. J. Forecast. 22, 553-568.

Nielsen, M.O., Johansen, S., 2012. Likelihood inference for a fractionally cointegrated vector autoregressive model. Econometrica, $2667-2732$.

Phillips, C.B.P., Perron, P., 1988. Testing for a unit root in time series regression. Biometrika 75 (2), 335-346.

Phylaktis, K., 1999. Capital market integration in the Pacific Basin Region: an impulse response analysis. J. Int. Money Financ. $19,267-287$. 
Rapach, D.E., Wohar, M.E., 2004. The persistence in international real interest rates. Int. J. Financ. Econ. 9, $339-346$.

Robinson, P.M., 1994. Efficient tests of nonstationary hypotheses. J. Am. Stat. Assoc. 89, 1420-1437.

Robinson, P.M., 1995a. Gaussian semi-parametric estimation of long range dependence. Ann. Stat. 23, $1630-1661$.

Robinson, P.M., 1995b. Log-periodogram regression of time series with long range dependence. Ann. Stat. $23,1048-1072$.

Robinson, P.M., Yajima, Y., 2002. Determination of cointegrating rank in fractional systems. J. Econ. 106, $217-241$.

Rose, A.K., 1988. Is the real interest rate really stable? J. Financ. 43, 1095-1112.

Sekioua, S., Zakane, A., 2007. On the persistence of real interest rates: new evidence from long-horizon data. Quant. Qual. Anal Social Sci. 1 (1), 63-77.

Shea, G., 1991. Uncertainty and implied variance bounds in long memory models of the interest rate term structure. Empir. Econ. 16, $287-312$.

Shiller, R.J., 1979. The volatility of long-term interest rates and expectations models of the term structure. J. Political Econ. 87 (6), $1190-1219$.

Sowell, F., 1992. Maximum likelihood estimation of stationary univariate fractionally integrated time series models. J. Econ. 53, $165-188$.

Sun, Y., Phillips, P.C.B., 2004. Understanding the fisher equation. J. Appl. Econ. 19, 869-886.

Taylor, J.B., 2013. International Monetary Policy Coordination: Past, Present and Future, BIS Working Paper No. 437.

Tkacz, G., 2001. Estimating the fractional order of integration of interest rates using wavelet OLS estimator. Stud. Nonlinear Dyn. Econ. 5, 1-21.

Tsay, W.J., 2000. The long memory story of the real interest rate. Econ. Lett. 67, 325-330. 